\title{
PREDIKSI JUMLAH MAHASISWA BARU UNIVERSITAS MALIKUSSALEH MENGGUNAKAN METODE DMA (DOUBLE MOVING AVERAGE)
}

\author{
Mukti Qamal ${ }^{1}$, Safwandi ${ }^{2}$, Tri Wulandari ${ }^{3}$ \\ Program Studi Teknik Informatika \\ Universitas Malikussaleh \\ mukti.gamal@unimal.ac.id \\ safwandihsst4@gmail.com \\ sriwulandari1755@gmail.com
}

\begin{abstract}
Abstrak
Abstrak - Peramalan (Forecasting) adalah metode untuk memperkirakan suatu nilai dimasa depan dengan menggunakan data masa lalu. Peramalan juga dapat diartikan sebagai seni dan ilmu untuk memperkirakan kejadian pada masa yang akan datan. Meningkatnya mahasiswa baru Universitas Malikussaleh membuat pihak biro kuwalahan menampung mahasiswa tersebut.Untuk itu pihak Biro Universitas Malikussaleh membutuhkan sebuah aplikasi yang dapat meramalkan jumlah mahasiswa baru ditahun mendatang. Aplikasi peramalan ini akan dibuat dengan menggunakan salah satu metode Time Series. Metode time series didasarkan pada serangkaian data-data berurutan yang berjarak sama (misalnya: mingguan ,bulanan, tahunan, dll). Aplikasi Prediksi Jumlah Mahasiswa Baru Universitas Malikussaleh merupakan Aplikasi yang dirancang menggunakan UML dan diimplementasikan dengan menggunakan bahasa pemograman Web seperti PHP dan HTML. Aplikasi ini dirancang dengan memasukkan sampel data jumlah mahasiswa baru yang diperoleh dari bagian Biro Universitas Malikussaleh dan dikalkulasikan dengan menggunakan metode DMA (Double Moving Average) menggunakan ordo 4x4 yang memiliki nilai keakuratan bervariasi, mulai dari sangat baik cukup, hal ini dikarenan jumlah data yang berbeda - beda di setiap jurusan. Hasil dari peramalan tersebut disimpan dalam database di visualisasikan menggunakan grafik dan tabel. Aplikasi
\end{abstract}


ini akan menampilkan hasil peramalan jumlah mahasiswa baru Universitas Malikussaleh perfakultas dan perjurusan di tahun mendatang.

Kata Kunci : Forecasting, Time Series, DMA (Double Moving Average)

\section{Pendahuluan}

Meningkatnya mahasiswa baru Universitas Malikussaleh membuat pihak biro kuwalahan menampung mahasiswa baru tersebut. Pihak biro harus menyediakan fasilitas yang memadai agar mahasiswa baru tersebut mendapat fasilitas yang layak. Pihak biro juga harus merencanakan berapa kelas perkuliahan harus dibuka di setiap jurusan. Dari penjelasan di atas, pihak Biro Universitas Malikussaleh membutuhkan solusi agar dapat menyediakan segala fasilitas dan perencanaan yang dibutuhkan untuk mahasiswa baru tersebut. Untuk membantu pihak Biro Universitas Malikussaleh menemukan solusi penulis ingin membuat sebuah sistem yang dapat digunakan untuk memprediksi jumlah calon mahasiswa baru dengan salah satu metode Time Series. Metode time series didasarkan pada serangkaian data-data berurutan yang berjarak sama (misalnya: mingguan ,bulanan, tahunan, dll).

Berdasarakan uraian latar belakang di atas, penulis tertarik untuk membangun sebuah perangkat lunak dan merancanakannya dalam bentuk penulisan sebuah proposal tugas akhir dengan judul "Prediksi Jumlah Mahasiswa Baru Universitas Malikussaleh Menggunakan Metode DMA (Double Moving Average)"

\section{Metode Penelitian}

Dalam pengembangan system, digunakan langkah-langkah:

\section{Analisis Kebutuhan}

Tahap metode analisis merupakan tahap menganalisa sistem yang akan dirancang dan dibangun. Setelah analisa didapatkan maka langkah selanjutnya adalah merincikan hasil analisa. Hasil analisa tersebut akan menjadi acuan dari perancangan sistem yang dibangun. 


\section{Perancangan sistem}

Pada tahapan ini penulis melakukan perancangan menggunakan SublimeText, Langkah awal yang dilakukan adalah mendeskripsikan proses kerja sistem secara rinci menggunakan skema sistem. Kemudian mengimplementasikan hasil rancangan yang telah dideskripsikan menjadi sebuah aplikasi dengan tampilan user friendly.

\section{Hasil dan Pembahasan}

\subsection{Use Case Diagram}

Use case diagram merupakan pemodelan untuk kelakuan (belhavior) sistem yang akan dibangun, dan mendeskripsikan sebuah interaksi antara satu atau lebih actor dengan sistem tersebut, use case digunakan untuk mengetahui fungsi - fungsi yang ada di dalam sistem dan siapa saja yang berhak menggunakan fungsional itu.

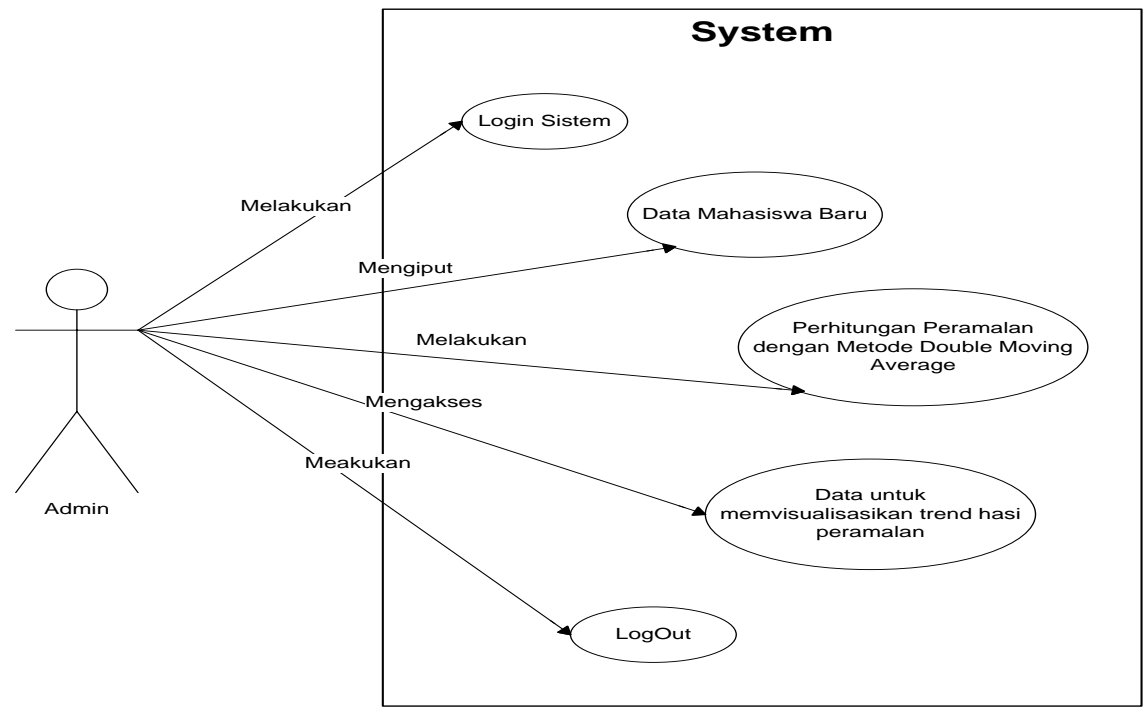

Gambar 1. Use case diagram 


\subsection{Activity Diagram}

Diagram aktivitas atau activity diagram menggambarkan aliran fungsionalitas sistem.Ada beberapa diagram aktivitas dalam perancangan ini, yaitu sebagai berikut:

\section{a. Activity Diagram Login Admin}

Admin membuka sistem, lalu sistem menampilkan halaman login kepada admin, kemudian admin mengisi username dan password. Selanjutnya sistem akan mengecek username dan password, jika admin benar mengisikan username dan password nya, maka sistem akan menampilkan halaman Home kepadaadmin. Dan jika admin salah, maka sistem akan menampilkan halaman login, lalu admin harus mengisikan username dan password nya kembali.Activity Diagram Login Admindapat dilihat di Gambar 2

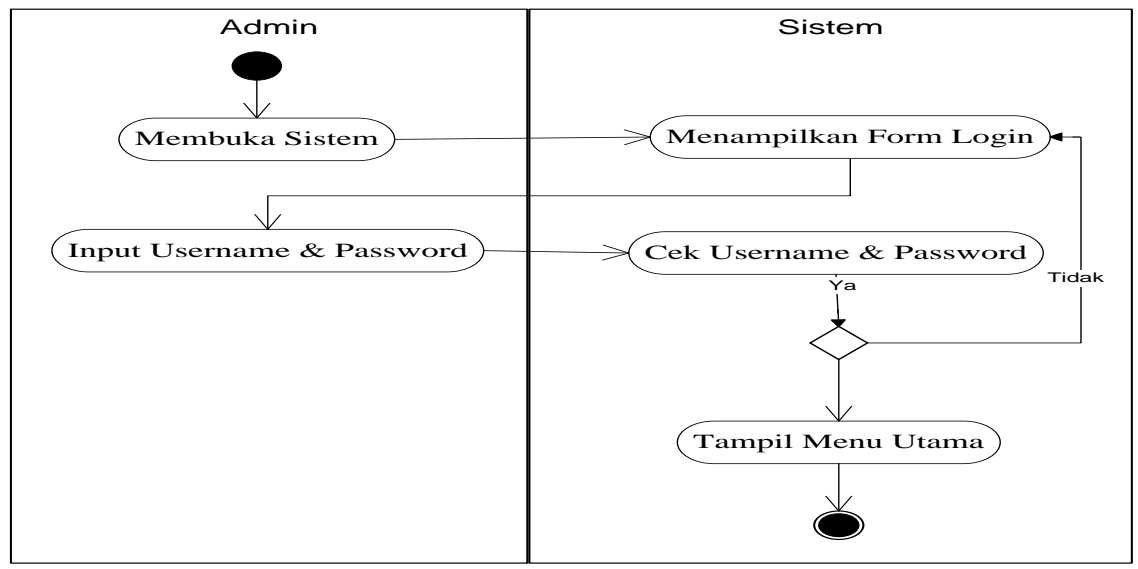

Gambar 2. Activity diagram Login Admin

\section{b. Activity Diagram Tambah dan Edit Data Mahasiswa Baru}

Admin Menekan menu Data Mahasiswa Baru, lalu sistem menampilkan Halaman Form mahasiswa baru, di dalam Form tersebut terdapat menu Tambah dan Edit, kemudian admin menambah atau mengedit data mahasiswa baru, selanjutnya admin menginput data mahasiswa yang baru, lalu klik botton tambah atau edit, selanjutnya sistem akan menyimpan data mahasiswa baru yang sudah ditambahkan atau yang sudah diedit, 
kemudian sistem menyimpannya, setelah itu sistem akan menampilkan halaman form data mahasiswa baru. Diagram tambah dan edit data mahasiswa baru ditunjukkan pada Gambar 3.

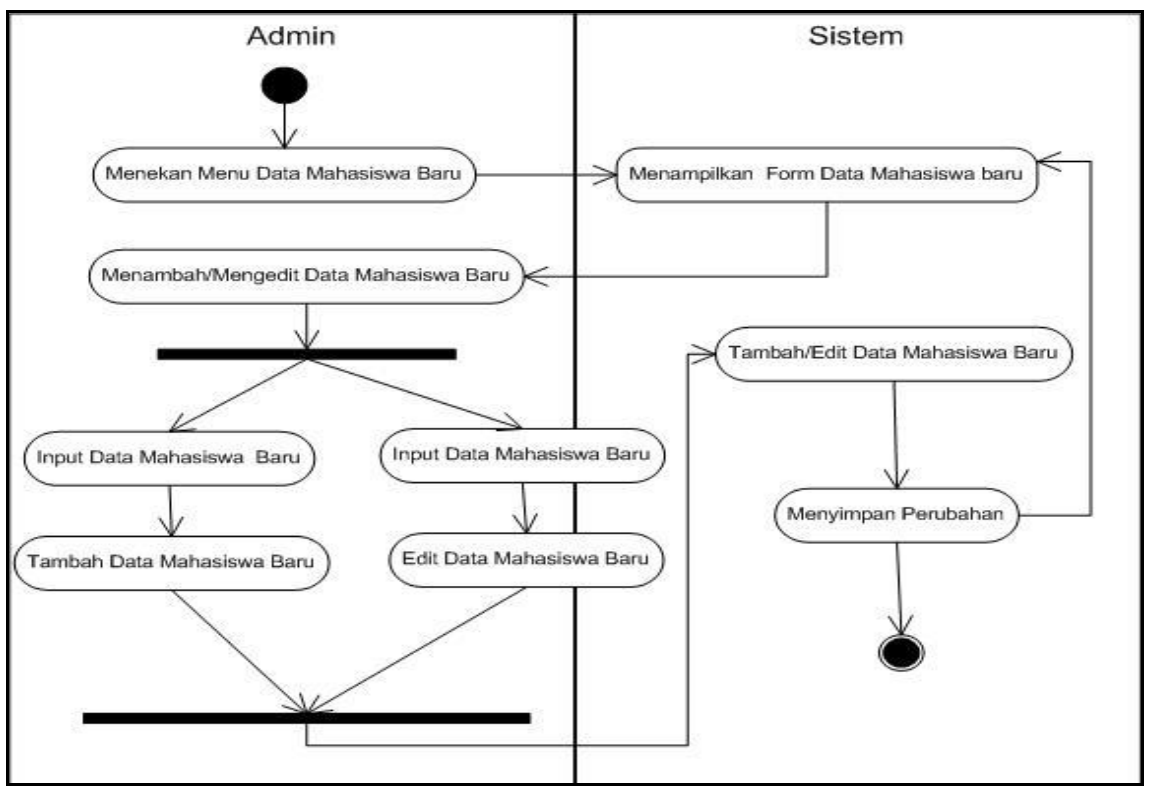

Gambar 3 .Activity diagram Tambah dan Edit Data Mahasiswa Baru

\section{c. Activity Diagram Pencarian manual menggunakan Metode Double Moving Average}

Admin melakukan login sistem memasukkan username dan password yang sudah didaftarkan sebelumnya. Kemudian sistem memverifikasikan username dan password. Jika salah admin harus mengulang login dan jika benar sistem akan menampilkan halaman home. Kemudian admin mengklik menu data mahasiswa baru untuk melakukan penginputan data mahasiswa baru. Selanjutnya admin mengklik menu hasil peramalandan melakukan perhitungan single moving average, double moving average, perhitungan nilai konstanta, perhitungan koefisien trend dan perhitungan hasil peramalan. Kemudian hasilnya sistem akan menampilkan trend grafik dan tabel dari hasil peramalan jumlah mahasiswa baru. Diagram aktifitas Cari perhitungan manual 
menggunakan metode Double Moving Average dapat dilihat pada Gambar 4.

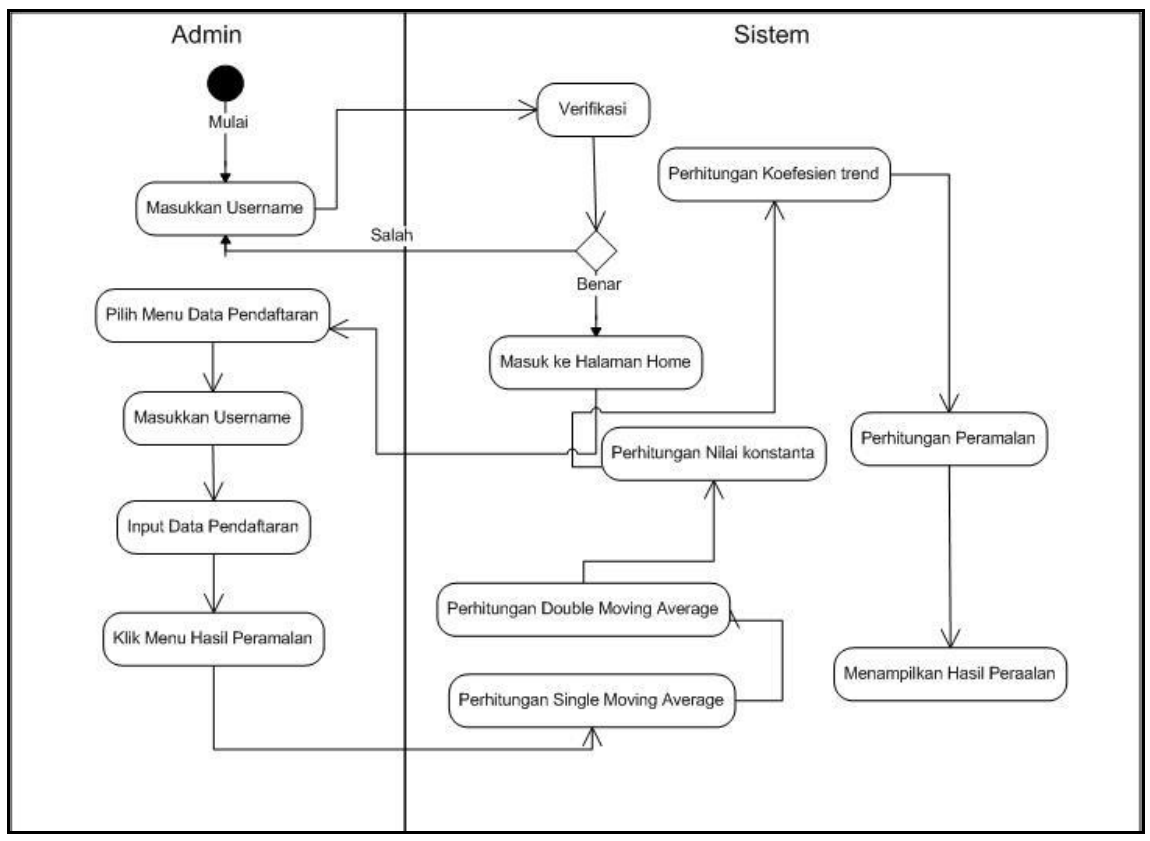

Gambar 4. Activity Diagram Pencarian manual menggunakan Metode Double Moving Average

\subsection{Sequence Diagram}

Diagram sekuensial atau sequence diagram digunakan untuk menunjukan aliran fungsionalitas dalam use case. Pada aplikasi ini terdapat beberapa sequence diagram, yaitu sebagai berikut:

\section{a. Sequence Diagram Login}

Admin Membuka sistem, lalu sistem akan menampilkan halaman login, kemudian admin menginputkan username dan password. selanjutnya sistem akan memvalidasi dan memverifikasi data login ke database, jika data yang diinputkan admin salah, maka admin harus menginputkan username dan password kembali, jika data yang dinputkan benar maka sistem akan menampilkan halaman home. Sequence diagram login dapat dilihat pada gambar 5. 


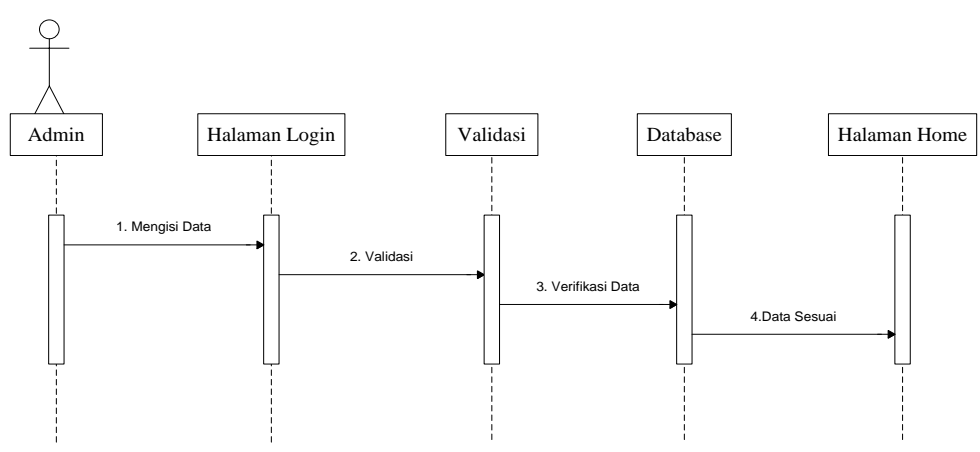

Gambar 5. Sequence diagram Login

\section{b. Sequence Diagram Tambah Data mahasiswa}

Diagram sequence di atas menunjukkan jalannya proses admin menambah data mahasiswa baru yang ada dalam sistem. Dimana setelah admin melakukan login kedalam sistem, maka sistem akan menampilkan halaman home. Untuk menambah mahasiswa baru, admin memilih menu tambah mahasiswa baru, dan sistem akan menampilkan form pengisian tambah mahasiswa baru. Setelah form data mahasiswa baru selesai, maka sistem akan menyimmpan data mahasiswa baru kedalam database, jika data berhasil disimpan, sistem akan menampilkan halaman form mahasiswa baru kembali.Sequence diagram tambah data mahasiswa dapat dilihat pada Gambar 6 .

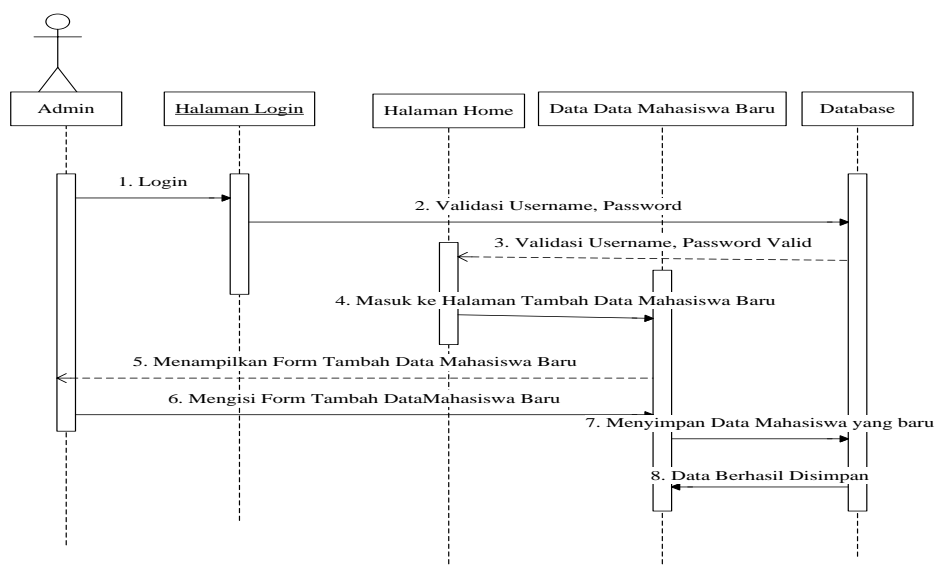

Gambar 6. Diagram Sekuen Tambah Data mahasiswa 


\section{c. Sequence Diagram Edit Data mahasiswa Baru}

Sequence Diagram menunjukkan jalannya proses admin mengedit data mahasiswa baru kedalam sistem. Dimana setelah admin melakukan login kedalam sistem, maka sistem akan menampilkan halaman home. Untuk mengedit data mahasiswa baru, admin memilih menu edit data mahasiswa baru, dan sistem akan menampilkan form edit mahasiswa baru. Setelah form mahasiswa baru selesai, maka sistem akan menyimpan data mahasiswa baru kedalam database, jika data berhasil disimpan, sistem akan menampilkan halaman form mahasiswa baru kembali. Sequence diagram edit data mahasiswa dapat dilihat pada Gambar 7.

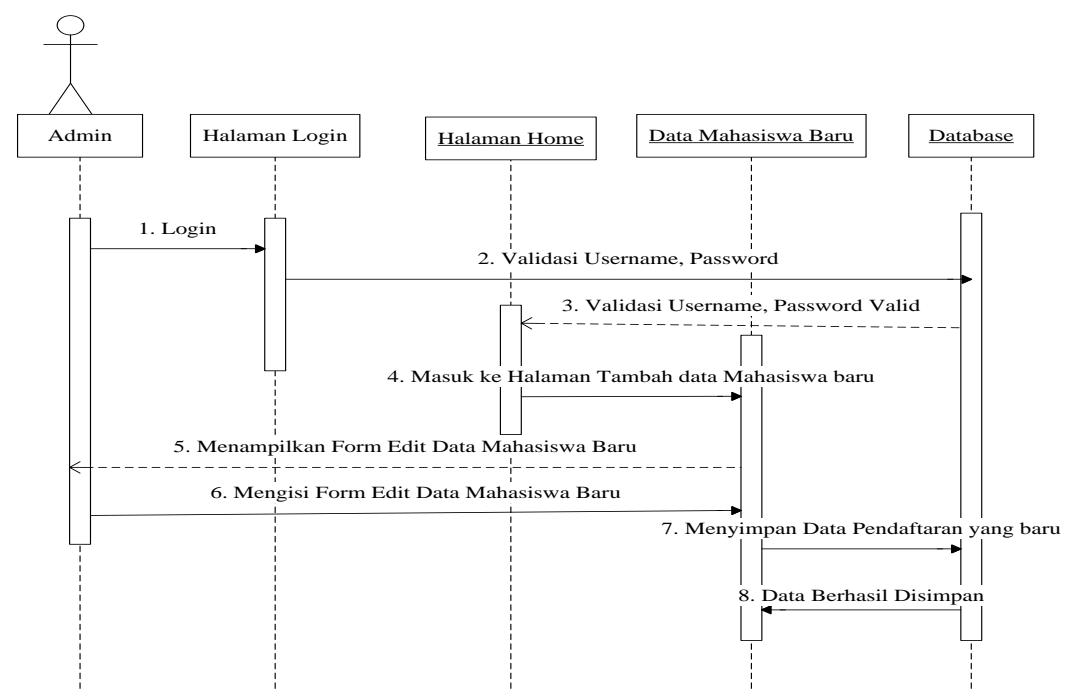

Gambar 7. Diagram Sekuen Edit Data mahasiswa

\section{d. Sequence Diagram Perhitungan Peramalan}

Diagram sequence di atas menunjukkan jalannya proses admin melakukan proses perhitungan peramalan dengan menggunakan metode Double Moving Average. Dimana setelah admin melakukan login kedalam sistem, maka sistem akan menampilkan halaman home. Untuk menghitung proses peramalan, maka admin memilih menu data mahasiswa baru, dan minginputkan data mahasiswa baru. Kemudian sistem akan langsung otomatis melakukan DOI: https://doi.org/10.29103/techsi.v11i3.1491 
perhitungan peramalan dan menampilkannya di menu halaman hasil peramalan. Setelah perhitungan peramalan data mahasiswa baru selesai, maka sistem akan menampilkan trend grafik dan tabel hasil peramalan jumlah mahasiswa baru ditahun mendatang. Diagram sekuen Perhitungan Peramalan dapat dilihat pada Gambar 8.

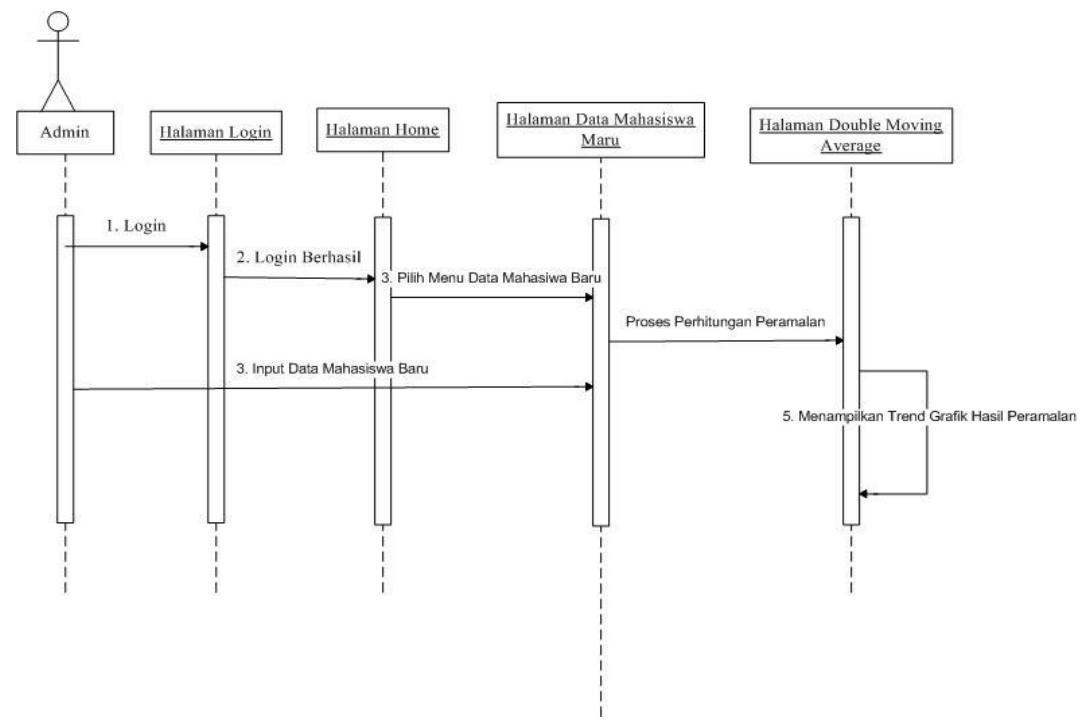

Gambar 8 Sequence diagram Perhitungan Peramalan

\subsection{Implementasi Antarmuka}

\section{a. Implementasi Halaman Login}

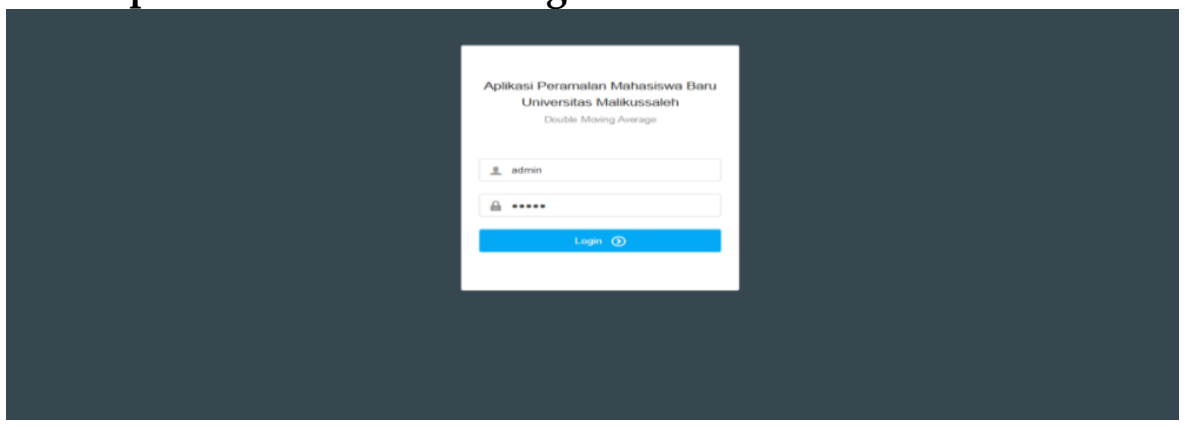

Gambar 9.Tampilan Halaman Login 
Halaman Login merupakan tampilan yang pertama kali dilihat saat aplikasi dijalankan.

\section{b. Implementasi Menu menu utama}

Menu Utama merupakan tampilan yang pertama kali dilihat saat user berhasil login. Di halaman ini tedapat menu Home, Data Mahasiswa Baru, Hasil Peramalan dan menu LogOut.

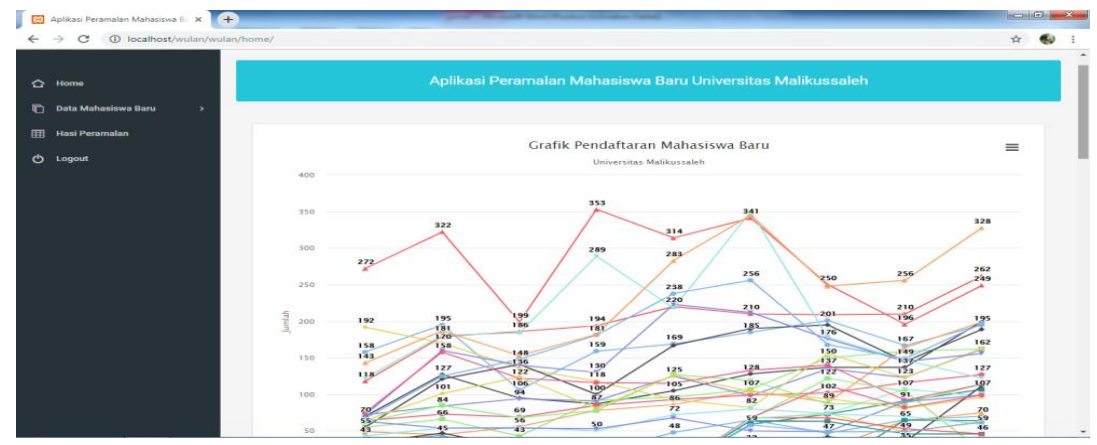

Gambar 10. Tampilan Menu utama

\section{c. Implementasi Menu Data Mahasiswa Baru}

Pada tampilan halaman data mahasiswa baru fakultas teknik ini, berisi seluruh data mahasiswa baru fakultas teknik perjurusan dari mulai tahun 2010-2018 dan pada halaman tersebut terdapat menu tambah data, edit data serta hapus data mahasiswa baru, seperti pada gambar 11 .

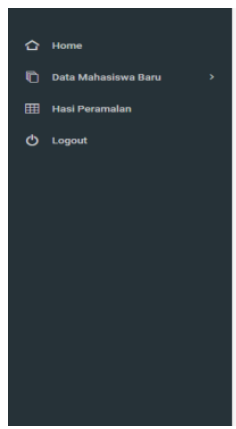

Data Mahasiswa Baru Fakultas Teknik

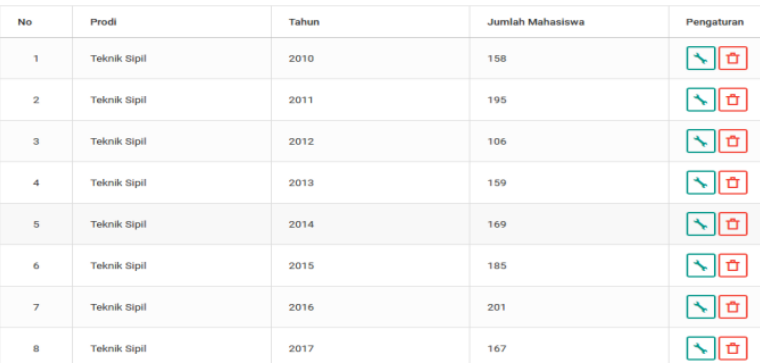

Gambar 11. Tampilan Menu Data mahasiswa baru 


\section{d. Implementasi Menu Hasil Peramalan}

Pada halaman ini sistem nyanyajikan pilihan list fakultas dan jurusan yang ingin diketahui hasil peramalan jumlah mahasiswa di tahun mendatang.Antarmuka ini dapat dilihat pada gambar 12.

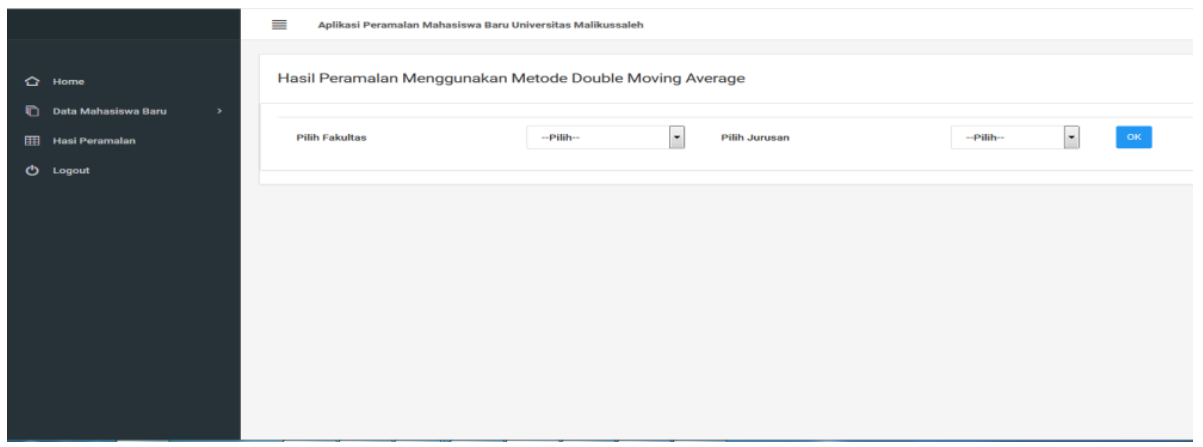

Gambar 12. Tampilan Menu Hasil peramalan

Halaman hasil peramalan Fakultas Teknik jurusan Teknik Informatika ini menyajikan data hasil peramalan dan bentuk grafik dan tabel. Dan pada grafik terdapat menu untuk mendownload data hasil peramalan.
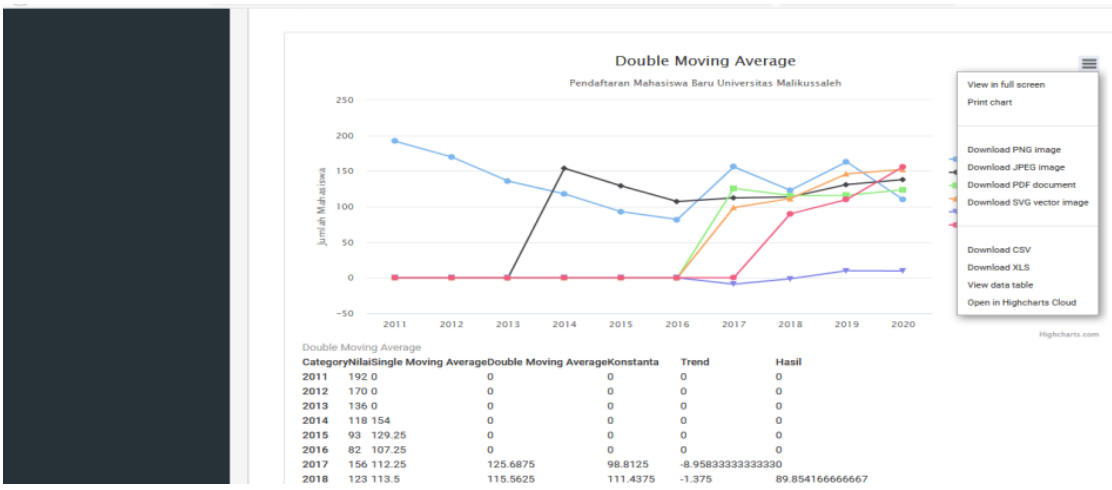

Gambar 13.Tampilan Menu Hasil peramalan Fakultas Teknik Jurusan Teknik Informatika 


\section{Kesimpulan}

Metode DMA (Double Moving Average) diimplementasikan dengan memasukkan sampel data yang didapat dari bagian Biro Universitas Malikussaleh. Sampel tersebut dikalkulasikan dengan menggunakan ordo $4 \times 4$ dan melalui beberapa tahap, mulai dari melakukan pencarian Single Moving Average, lalu hasil dari pencarian Single Moving Average di kalkulasikan menjadi pencarian Double Moving Average, kemudian menentukan konstanta dan mencari koefesien trend. Setelah itu akan menghasilkan nilai prediksi jumlah mahasiswa Baru Universitas Malikussaleh. Dalam penerapannya Aplikasi Prediksi Jumlah Mahasiswa Baru Universitas Malikussaleh menggunakan metode DMA (Double Moving Average) memiliki nilai SSE, MSE dan MAPE yang berbeda dalam setiap peramalan jumlah mahasiswa baru perjurusan. Hal ini di karenakan data jumlah mahasiswa baru dimasing- masing jurusan memiliki nilai yang berbeda di setiap tahunnya.

\section{Daftar Pustaka}

Cucus, A. (n.d.). Perancangan Sistem Informasi Klaim Asuransi Hatimah, I., Wahyuningsih, S., \& Sifriani. (2013). Perbandingan Metode Double Moving Average dan Pemulusan Eksponensial Ganda dari Holt dalam Peramalan Harga Saham. Eksponensial , 103-107.

Hudiyanti, C. V., Bachtiar, F. A., \& Setiawan, B. D. (2019).Perbandingan Double Moving Average dan Double Exponensial Smooting. Pengembangan Teknologi Informasi dan ILmu Komputer, 2667-2672.

Kadir, A. (2010). Dasar Aplikasi Database MySQL- Delphi. Yogyakarta: Andi.

Sari, I. P., Andrizal, \& Devianto, D. (2016). Perancangan Sistem Pengenalan Wajah Manusia Menggunakan Web Camera dengan Menggunakan Metode Summary Squared Error (SSE). 
Unknown. (2014, Agustus 28). Cara Peramalan dengan Metode Single Moving Average dan Double Moving Average.

Wardiah, S., \& Iskandar. (2016). Analisis Peramalan Penjualan Produk Kripik Pisang Kemasan Bungkus. Teknik Industri, 135-142.Jiwa Menggunakan Ms.Visual Basic 6.0. pada PT.Asuransi Jiwaraya Kota Bandar Lampung. Perancangan Sistem Informasi Klaim Asuransi Jiwa Menggunakan Ms.Vsual Basic 6.0. Pada PT. Asuransi Jiwarasraya Kota Bandar Lampung, 31-35. 